\title{
New technologies to treatment of Spotted Fever, GVE VII - Santo Andre, SP, Brazil.
}

\author{
Andrea M. Losacco ${ }^{1}$, Angela Maria M. Moriwake ${ }^{2}$, Simone C. Caravaggi ${ }^{2}$, Milena Camaral ${ }^{3}$ \\ ${ }^{1}$ Epidemiology, Infectology Institute "Emílio Ribas", Sao Paulo, Sao paulo, Brazil, ${ }^{2}$ GVE VII, Santo Andre, SP, Brazil, ${ }^{3}$ Department of Health \\ Surveillance, Diadema, SP, Brazil
}

\section{Objective}

To perform the spatial distribution of Spotted Fever in the Metropolitan Area of Sao Paulo Municipality (MRSP), coverage area of Epidemiological Surveillance Group VII - of Santo Andre (GVE7), to determine clusters of disease incidence, and through QR Code to be able to access data from any smartphone as an aid to the early treatment of new suspected cases.

\section{Introduction}

The use of new technologies such as Online Maps and the QR Code facilitates the knowledge dissemination in the health science, aiding in diagnostic elucidation and intelligent decisions making, thus offering an improvement in the quality of care provided to patients. Cases with suspected spotted fever should be approached as potentially serious, which may develop with shock within a few hours and, if not addressed can progress to death. In the case of spotted fever, early onset determines the cure of these cases.

\section{Methods}

The spatial distribution of confirmed Spotted Fever cases was performed in the region of the seven municipalities inserted into GVE7, using the Information System of Notifiable Diseases (SINAN) database and Google Maps online tool, and determining clusters of disease incidence. The QR Code was generated through the QR Code Maker online tool to access map and to verify if the displacement of each new suspect case coincides with the incidence clusters of the disease, and to determine early treatment of these patients.

\section{Results}

During the study period, 496 suspected cases of Spotted Fever were reported, of which 64 cases were laboratory test confirmed with a lethality rate of $65 \%$. Most of the probable infection sites are located near the regions close to forest remnants and near the dams. The main concentration of cases is in Recreio da Borda do CampoDistrict in Santo Andre, 27 cases (43\% of total). The other priority areas for Spotted Fever occurrence in the MRSP in the period were the districts of Alvarenga, Cooperativa (border of Municipality of Diadema), and Montanhao (in the Municipality of Sao Bernardo do Campo). Figure 1. QR Code and Google Maps Spotted Fever Incidence Clusters, GVE VII Santo Andre.

\section{Conclusions}

In order to validate the use of these technologies as positive, it will be necessary to analyze the closure of the new suspected Spotted Fever cases treated in the region studied. Positive spatial correlation between neighboring areas may result from the disease having an occurrence characteristic in endemic areas and spreading to the nearest areas. We can conclude that the use of new technologies to determine the early onset of treatment for Spotted Fever suspected cases based on the origin of the patients treated in the region of GVE7 can determine the success in the evolution of these cases.

\section{Acknowledgement}

Milena CamaraI - Health Department Municipality of Diadema. 


\section{References}

Barros-Silva PM, Pereira SV, Fonseca LX, Maniglia FV, de Oliveira SV, de Caldas EP. Febre maculosa: uma análise epidemiológica dos registros do sistema de vigilância do Brasil. Scientia Plena. 2014 Apr 25;10(4 (A)).

Biggs HM. 2016. Diagnosis and management of tickborne rickettsial diseases: Rocky Mountain spotted fever and other spotted fever group rickettsioses, ehrlichioses, and anaplasmosis-United States. MMWR Recomm Rep. 65, 1-44. PubMed https://doi.org/10.15585/mmwr.rr6502a1

Czuszynski K, Ruminski J. Interaction with medical data using QR-codes. InHuman System Interactions (HSI), 2014 7th International Conference on 2014 Jun 16 (pp. 182-187). IEEE.

Dube S, Ndlovu S, Nyathi T, Sibanda KQR. Code based patient medical health records transmission: Zimbabwean case. InProceedings of informing science \& IT education conference (InSITE) 2015 (pp. 521-520).

Kanzaki A, Natsuaki M, Matsutani S, Mase K, Nakajima E, et al. 2018. Two cases of Japanese spotted fever infected in Rokko mountain near urban area of southern Hyogo Prefecture. J Dermatol. 45(6), e146-47. doi:https://doi.org/10.1111/1346-8138.14208. PubMed

Nasser JT, Lana RC, Silva CM, Lourenço RW, Silva DC, et al. 2015. Urbanização da febre maculosa brasileira em município da região Sudeste: epidemiologia e distribuição espacial. Rev Bras Epidemiol. 18, 299-312. PubMed https://doi.org/10.1590/1980-5497201500020002

Parra F. 2016. Reflexões sobre as relações entre usuário-interator e tecnologias emergentes a partir do QR Code. Temática. 2018 May 23;14(5). Pinter A ET AL.; A Febre Maculosa Brasileira na Região Metropolitana de São Paulo. Boletim Epidemiológico Paulista. 13(151), 3-47.

Raghavan RK, Goodin DG, Neises D, Anderson GA, Ganta RR. 2016. Hierarchical bayesian spatio-temporal analysis of climatic and socio-economic determinants of rocky mountain spotted fever. PLoS One. 11(3), e0150180. PubMed https://doi.org/10.1371/journal.pone.0150180

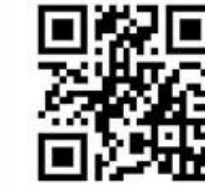

http://goo.gl/i1TMsX

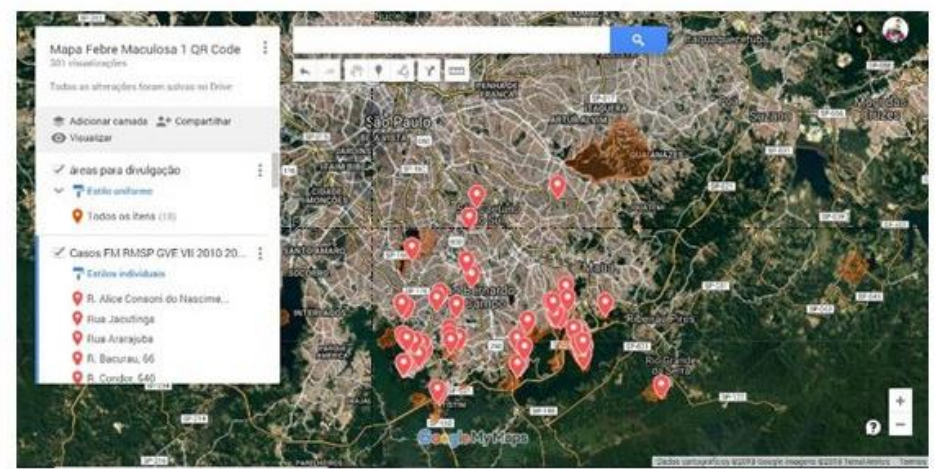

Figure 1.

ISDS Annual Conference Proceedings 2019. This is an Open Access article distributed under the terms of the Creative Commons AttributionNoncommercial 4.0 Unported License (http://creativecommons.org/licenses/by-nc/3.0/), permitting all non-commercial use, distribution, and reproduction in any medium, provided the original work is properly cited. 